\title{
Impact of Nano additives on optimized Mahua Bio-diesel Performance
}

\author{
U. S. Jyothi ${ }^{* 1}, G$. Jeevan Kumar ${ }^{2}$ \\ ${ }^{1}$ Professor, GRIET, Mechanical Engineering Department, Hyderabad, India \\ ${ }^{2}$ PG student, GRIET, Mechanical Engineering Department, Hyderabad, India
}

\begin{abstract}
In both industrial and transportation sectors, petroleum consumption has been increasing tremendously. It is known that increase in demand of fossil fuels leads to exhaust of petroleum products in future. Biofuel is a fuel made by chemically reacting alcohol with vegetable oils, fats, or greases, such as recycled restaurant greases. The metal-based additives are used in order to improve the quality of fuel by reducing the unburn hydrocarbons in IC engines, to minimize the exhaust gas harmful emissions. In the present experimental work, an attempt is made at investigating the effect of Aluminum oxide and copper oxide nanoparticles addition in Mahua biodiesel in a single cylinder water cooled direct injection four stroke diesel engine. Initially experiments are conducted to optimize the blend of transeterified Mahua oil with diesel fuel with respect to Combustion, performance and emission parameters. The nano fluids have been prepared from $50 \mathrm{ppm}$ concentrations of Aluminum oxide and copper oxide separately, through an ultrasonication process. For optimized biodiesel of Mahua oil, the effect of nano additives on Combustion characteristics viz cylinder pressure, Heat release rate, performance parameters such as BTE, BSFC and emission parameters $\mathrm{HC}, \mathrm{CO}, \mathrm{CO}_{2}, \mathrm{NOx}$ emissions were evaluated and compared. In $\mathrm{CI}$ engines, with biodiesel usage reduces the emission particulates to the significant extent. Due to the presence of oxygen content in bio diesel, which causes increase in NOx formation. In this work there is significant reduction in emission oxides of nitrogen is noticed with nano additives due to control of in-cylinder temperature. Key words: Combustion, Nano fluids, Heat release rate, Cylinder pressure, Emissions
\end{abstract}

\section{Introduction}

Biofuels production as an alternative and renewable energy source to replace the Petroleum based fuel supplies. Biodiesel fuels are suitable with the current fuel system and can be used without modification in diesel engines. This is the world's fastest rising alternative fuel for transportation. Because of good combustion properties, vegetable oils are considered one of the effective replacement fuels for internal combustion engines. It is the world's fastest-growing alternative fuel for transport. Because of the desirable combustion properties for many applications non edible oils are treated as one of the most effective natural fuels. The main cause of encouraging the internal combustion engine to look for alternative fuels is concerned about the problems associated with gasoline engine pollution.

In this scenario, bio-diesel is seen as the best alternative fuel for various sectors such as transport, agriculture, manufacturing, etc. Its production also creates jobs for rural people by planting plants which produce vegetable oil [1]. Biodiesel has desirable combustion properties and non-toxic biodegradability as it derived from local and renewable resources. It has been stated that the availability of 26 species of fatty acid methyl esters makes appropriate use as substitute fuel [2]. One of the motives for consuming Mahua oil as biodiesel is diminished emission trends because of its favourable combustion behaviour in comparison with diesel. Approximately a one-third yield of Mahua oil is found with its seeds by weight and is comestible and mostly in soap and production of glycerine. The heating value in comparison with diesel is $88.26 \%$ on weight basis and $96.3 \%$ on volume-basis [3]. The readiness of oxygen in the biodiesel enhances the heat in the combustion chamber at the end of the compression phase, leads to reduction of the emission particulates except oxides of Nitrogen emissions [4]. Mahua biodiesel preparation and its characteristics were considered to achieve lesser output of power and emissions on diesel engines [5]. It is reported that with biodiesel $\mathrm{HC}$ emissions are reduced by $16.2 \%$, CO emissions are reduced by $11.4 \%$, carbon dioxide emissions are reduced by $5.3 \%$ because of the presence of oxygen content. An enhancement of 8.4 percent in Nitrogen oxide emissions with optimal blend of Mahua methyl ester compared to diesel at peak load. Biodiesel exhibits higher cylinder temperatures as it contains higher oxygen content, leads to intensification of oxides of nitrogen emissions [6].

Modern nanotechnology offers great opportunities to process and manufacture materials with an average

\footnotetext{
* Corresponding author: upendram_jyothi@yahoo.com
} 
crystalline size of less than $50 \mathrm{~nm}$ and to apply the same to increase the thermal conductivity of fluids through dispersion [7, 8]. Using biodiesel nano additives, the obtained results conveyed enhanced fuel characteristics in improving the efficiency of combustion apart from reduction in harmful emissions. For Mahua biodiesel with nano additive is very much suitable as a substitute fuel for diesel engine to improve performance and emissions $[9,10]$. Biodiesel with oxygenated and metal oxide the addition shows less emission particulates at rated loads than fractional loads, resulting in lower BSFC, NOx, $\mathrm{HC}, \mathrm{CO}_{2}$ emissions [11,12]. The peak pressure of combustion and rate of heat release are improved with the addition of aluminum nano additive for Mahua methyl ester blend fuelled by the direct injection with approach of common rail type in diesel engine, leads to reduction in delay in ignition [13]. The BTE is enhanced by approximately $3 \%$ with nano additive of $\mathrm{ZnO}$ when compared to diesel, further diminishing in NOx emissions has been noticed [14]. By influencing $25 \mathrm{ppm}$ Titanium nano additives, it is noticed that there is improvement in-cylinder pressure and heat release rate with reduced emissions, further 25 ppm Zirconium nano additives, reduced cylinder pressure and increased $\mathrm{HC}$ emissions and reduced $\mathrm{CO}$, smoke emissions have been noticed [15]. This study is focused to present the impact of nano additives on characteristics of diesel Engine which is operated by using optimised Mahua biodiesel

\section{MATERIALS \& PROCEDURE FOR THE EXPERIMENTATION}

\subsection{Preparation of Mahua Biodiesel}

As Mahua oil has high viscosity which leads to combustion problems such as handling of fuel, weak atomization, pressure of injection etc., the only solution to overcome these limitations is Transesterification of the oil. In the present work, to reduce the viscosity Transesterification is execute with alkali catalyst to have quicker reaction process. In this process, $500 \mathrm{ml}$ of Mahua oil and methanol of $200 \mathrm{ml}$ are assorted including 5 grams $\mathrm{NaOH}$, which is placed for $2 \mathrm{hrs}$ at approximately to $640^{\circ} \mathrm{C}$ in ultrasonicator to have stirring arrangement along with heating. Then it is retained in the condition for 8 to $10 \mathrm{hrs}$ to separate glycerol from biodiesel. Further, any content of moisture in bio-diesel was sweep away for two times with distilled water and heated above $100^{\circ} \mathrm{C}$ to eliminate the acids. The aesthetic appearance of transeterified Mahua oil is shown in Fig1. In this investigation, for characteristic parameters of the diesel Engine evaluation the optimised blend i.e, 20\% blend of Mahua biodiesel is chosen.

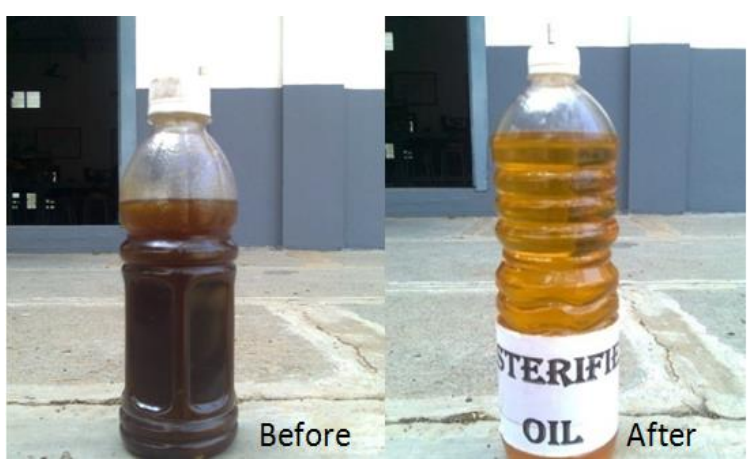

Fig. 1. Before and after transesterification process of Mahua oïl

\subsubsection{Nano additives}

Nano powders each of $50 \mathrm{ppm}$ of alumina (Al2O3) and copper oxide $(\mathrm{CuO})$ are supplemented distinctly to the optimal blend of Mahua Biodiesel. It was blended well after adding nanofluid, then it was poured into an apparatus where to be agitated with ultra-sonication shaker for about 45 minutes to render even absorption of biodiesel with nano powder addition. The properties of four different cases of fuel involved in the present study are given in Table 1 .

Table 1. Properties of four fuel cases of the study

\begin{tabular}{|c|c|c|c|c|}
\hline $\begin{array}{l}\text { Characteristic } \\
\text { Property }\end{array}$ & $\begin{array}{l}\text { Diesel } \\
\text { Fuel }\end{array}$ & $\begin{array}{l}\text { Biodiesel } \\
\text { (BD) }\end{array}$ & BDA1 & $\mathrm{BDA} 2$ \\
\hline $\begin{array}{l}\text { Heating value } \\
\text { in } \mathrm{MJ} / \mathrm{kg}\end{array}$ & 42.9 & 37.8 & 41.69 & 43.12 \\
\hline $\begin{array}{l}\text { Density } \\
\text { in } \mathrm{gm} / \mathrm{cc}\end{array}$ & 0.841 & 0.844 & 0.827 & 0.842 \\
\hline $\begin{array}{l}\text { Viscosity } \\
\text { in cSt }\end{array}$ & 3.59 & 5.89 & 3.37 & 4.3 \\
\hline cetane number & 47 & 62 & 49 & 49.5 \\
\hline $\begin{array}{l}\text { Flash point } \\
\text { in }{ }^{0} \mathrm{C}\end{array}$ & 64 & 158 & 71 & 60 \\
\hline $\begin{array}{l}\text { Fire point } \\
\text { in }{ }^{0} \mathrm{C}\end{array}$ & 78 & 162 & 78 & 66 \\
\hline
\end{tabular}

\subsection{Experimentation Procedure}

The Experimentation is proceeded on 4 stroke single cylinder diesel engine with water cooling and ratings are stipulated in Table 2. An AvL Combustion analyzer and AvL exhaust Gas analysers were used for evaluation of the main characteristics of combustion and Emission particulates. A Line diagram with all accessories of the test engine is shown with Fig 2. Initially, without imparting any load the test engine was run for certain duration to achieve stable condition. 
Table 2. Design parameters of the test engine

\begin{tabular}{|l|l|}
\hline Rated Power & $5 \mathrm{HP} / 3.7 \mathrm{~kW}$ \\
\hline Length of the Stroke & 11 centimeters \\
\hline Bore diameter & 8 centimeters \\
\hline Rated speed & 1500 revolution per minute \\
\hline Compression ratio & $16.5: 1$ \\
\hline Number of cylinders & 1 \\
\hline Swept volume & 550 cubic centimeters \\
\hline Fuel injection timing & $21^{0}$ Before TDC \\
\hline
\end{tabular}

Using the current dynamometer as loading device, combustion and emission parameters were reported for various fractional loads in stages. Experiments were performed using Mahua Methyl Ester Biodiesel with 20 percent blend without and with of nano additives of 50 ppm $\mathrm{Al} 2 \mathrm{O} 3$ and $\mathrm{CuO}$ separately at five different loads i.e., at evaluated brake powers of $0.61,1.08,1.83,2.22$ and $2.86 \mathrm{~kW}$ respectively, for efficiency, combustion and emission parameters assessment.

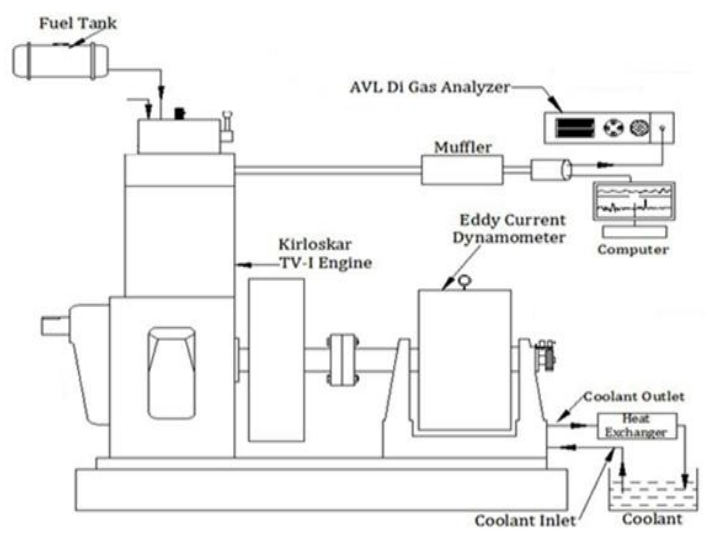

Fig 2. Experimental set up line diagram

\section{Results and discussions}

\subsection{Cylinder Pressure}

A distinction between pressure inside the cylinder and crank angle (CA) is presented in Fig 3. Using combustion analyzer for crank angle range of $-180^{\circ} \mathrm{CA}$ before top dead centre (BTDC) to 180 degrees CA after top dead centre (ATDC), the cylinder pressure is noted for the purpose of analysis. For the optimal blend of biodiesel, the pressure at maximum load is perceived less compared to diesel. Biodiesel mixture displays a decrease of 4 percent. because of the lower heating value and rate of fire intensity. There is an improvement of about $5.7 \%$ in cylinder pressure with $\mathrm{Al}_{2} \mathrm{O}_{3}$ nano additive and $15.9 \%$ with $\mathrm{CuO}$ nano additive as compared with bio diesel blend. Unlike to biodiesel, where peak pressure is noticed at ATDC, with nano additives it occurs at TDC. This contributed to improve the performance characteristics due to boosted temperature inside the cylinder.

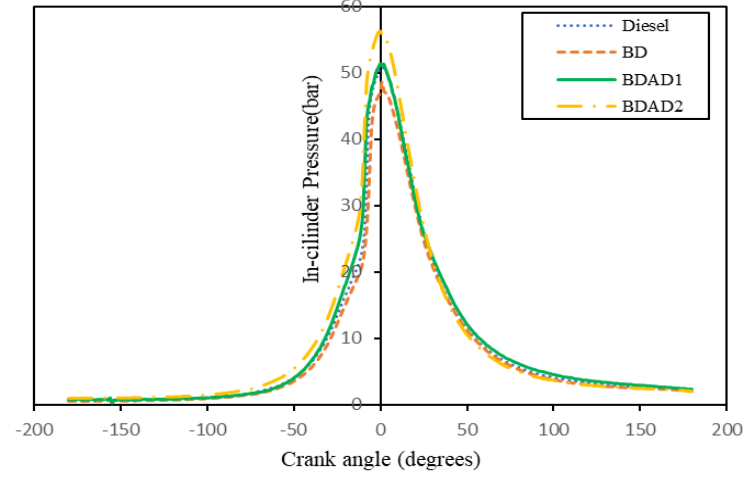

Fig 3. Variation of In-Cylinder pressure vs CA

\subsection{Rate of Heat Release}

The rate of heat release (HRR) was evaluated from $30^{\circ}$ CA BTDC to $90^{\circ}$ ATDC and Fig 4 shows the trends of all four cases of the fuel. In comparison with diesel, the rate of heat release is fewer with biodiesel i.e. $3.07 \%$ reduction is noticed. The HRR peak value of $106.6 \mathrm{~kJ} /$ $\mathrm{m} 3$-deg for biodiesel which is observed at $10^{\circ} \mathrm{CA}$ BTDC, whereas for diesel the value is $110 \mathrm{~kJ} / \mathrm{m}^{3}-\mathrm{deg}$ at $11^{0}$ CA BTDC. A betterment on HRR for biodiesel with each nano additive compared to diesel, owing to the effective firing of the fuel mixture with superior quality. An increase around $15.4 \%, 20.6 \%$ are observed for $\mathrm{Al}_{2} \mathrm{O}_{3}$ and $\mathrm{CuO}$ additives respectively at $11^{\circ} \mathrm{CA}$ BTDC due to the improvements in combustion with a limited quenching and a reasonable delay in ignition may be attributed to the improvement.

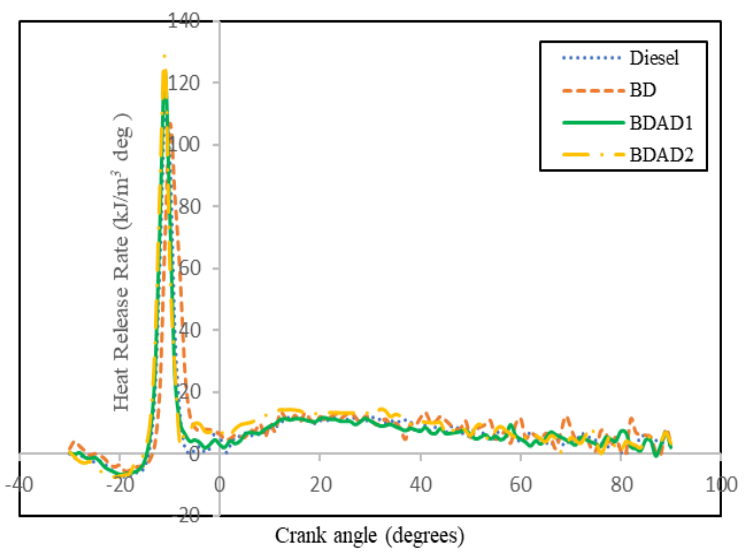

Fig 4. Variation of HRR vs CA

\subsection{Brake Thermal Efficiency}

Demonstrations of BTE variability for specific applied loads for different cases of fuels are presented in Fig 5. At part loads, the Mahua methyl ester-based bio diesel's thermal efficiency relative to brake power was inferior to that of diesel. 


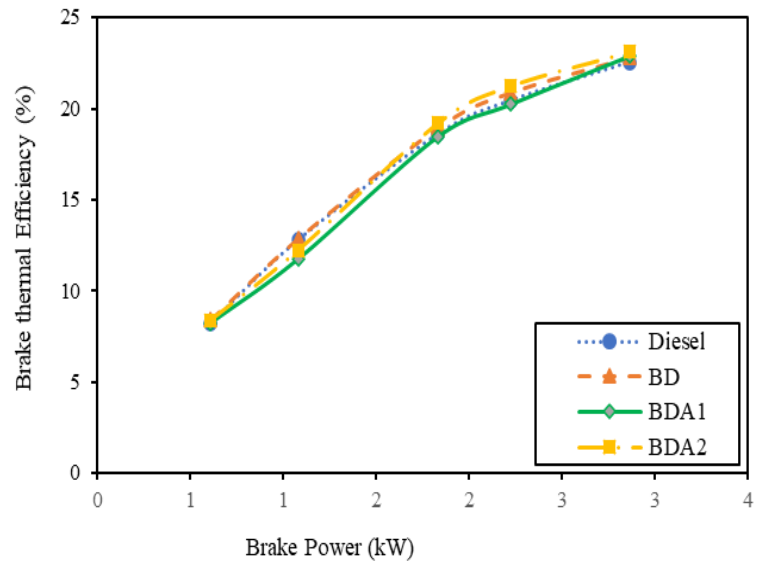

Fig 5. Variation of BTE $v s$ BP

This is because of low explosiveness, viscosity and higher density of Mahua biodiesel leads to poor formation of mixture at low loads than tidy diesel. At full load with mahua biodiesel, it was detected that at $20 \%$ Mahua methyl ester blend; there is a small upgrading of $1 \%$ in $\mathrm{BTE}$. It was also noted that there is a gain of $0.5 \%$ and $1.4 \%$ BTE with $\mathrm{Al}_{2} \mathrm{O}_{3}$ and $\mathrm{CuO}$ nano particle additives respectively. The origin may be because of increased volume-surface ratio of nano fuels which enable more fuel injected to react with water.

\subsection{Specific fuel consumption (BSFC)}

The BSFC variance with brake energy is shown at various loads for all fuel cases in Fig 6. It is noted that for all conditions, the reduction in BSFC is found from part loads to full load. The specific fuel consumption is $0.406 \mathrm{~kg} / \mathrm{kW}-\mathrm{hr}$ for standard engine with diesel operation at rated load. Whereas, with Mahua biodiesel it is increased by $2.5 \%$ because of increased viscosity and poor biodiesel mixture formation. It is observed that the maximum load with BDA1 and BDA2 is reduced by 1.6 percent and 4 percent compared to BD in BSFC. The reason may be due to the increased oxidation potential at higher loads with nano additives than with part loads.

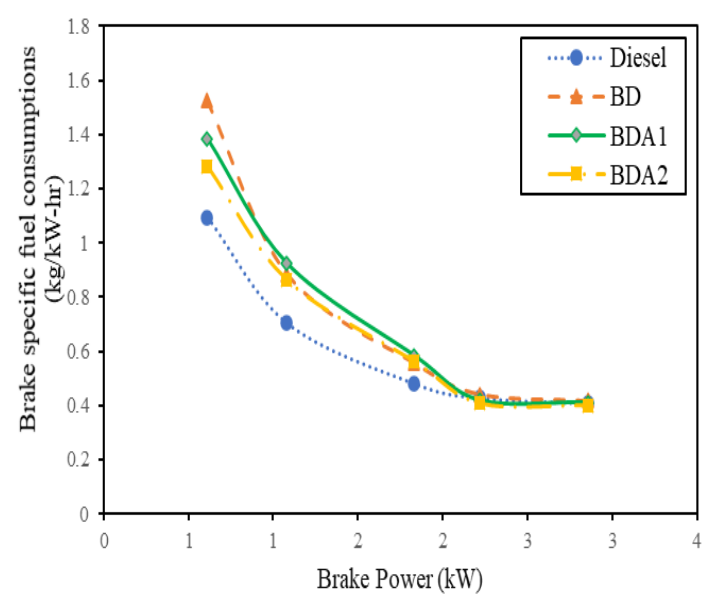

Fig 6. Variation of BSFC $v s$ BP

\subsection{Emission particulates of Hydrocarbon}

The Fig 7, demonstrates the dissimilarities of hydrocarbon emissions for diesel and biodiesel and with additives cases. An increased trend is detected with increase of load. At the rated load, $16.2 \%$ reduction is noticed with Mahua biodiesel. The use of oxygen in biodiesel contributes to effective burning of the fuel and thus to reduce the hydrocarbons emission particulates. It was also found that, relative to $\mathrm{Al} 2 \mathrm{O} 3$ and $\mathrm{CuO}$ additives, there is a reduction of $5.5 \%$ and $7.9 \%$ in emissions. This is attributed, because of energy release by nano additives during expansion stroke in addition to the liquid fuel.

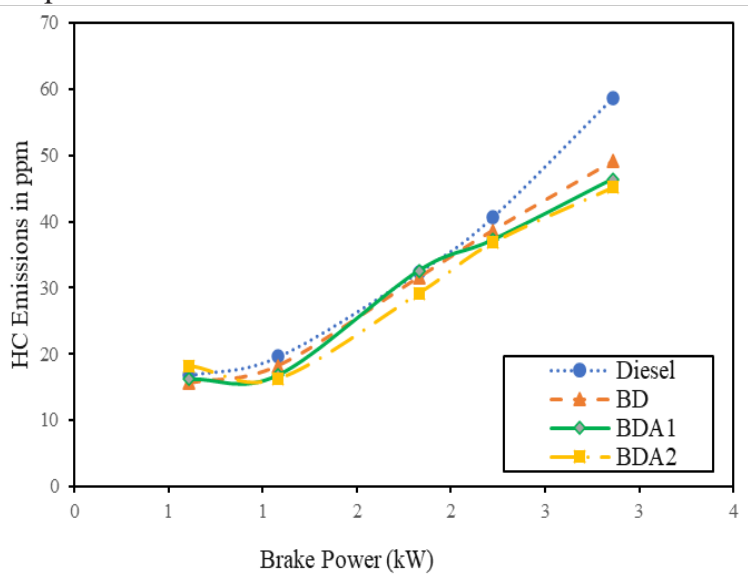

Fig 7. Variation of Hydro Carbon emissions vs BP

\subsection{Emissions of Carbon monoxide}

For all fuel cases of the study, with and without additives, the range of carbon monoxide emissions is depicted in Fig 8 at distinct loads and the trend observed is in growing with accumulation of loads. At rated load, the drop of CO particulates was noted as $11.4 \%$, due to the accessibility of the oxygen in biodiesel to assist the burning of the fuel. With $\mathrm{Al}_{2} \mathrm{O}_{3}$ and $\mathrm{CuO}$ nano additives, there is a further reduction of $8.3 \%$ and $10.5 \%$ respectively at higher loads. This reason assigned may be improved atomization by micro-explosion events, thereby lowers the creation of emissions.

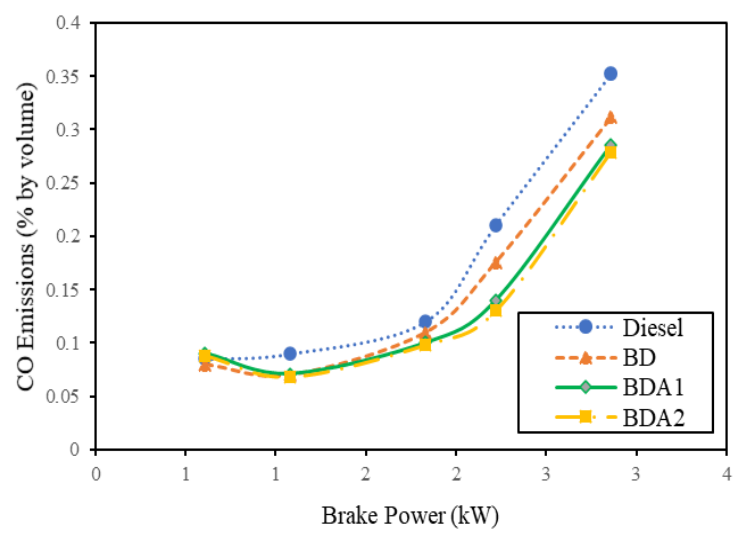

Fig 8. Variation of CO Emissions vs BP 


\subsection{Emissions of Carbon dioxide}

For four different cases of study, Fig 9 shows dissimilarity of $\mathrm{CO}_{2}$ particulates at five fractional loads. For Mahua methyl ester blend (BD) the emission was reduced by $5.2 \%$ as that of conventional fuel. The reason may assign as the availability of oxygen in Mahua biodiesel leads to effective firing resulting reduction in $\mathrm{CO}_{2}$ emission. Apart, the emissions were reduced by $4.6 \%$ \& $6.9 \%$ with addition of metal additives of $\mathrm{Al}_{2} \mathrm{O}_{3}$ and $\mathrm{CuO}$ respectively compared to MME biodiesel due to micro explosion, the adequate air/fuel mixing.

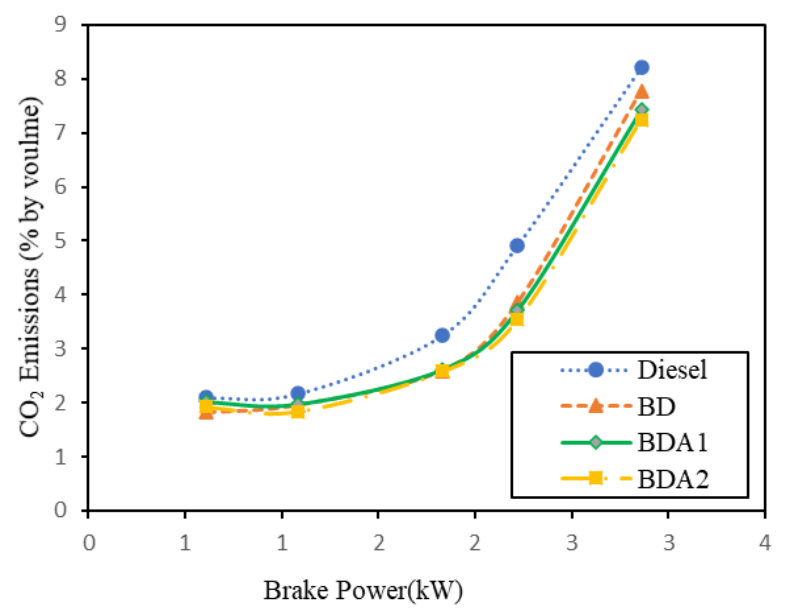

Fig 9. Variation of $\mathrm{CO}_{2}$ emissions vs $\mathrm{BP}$

\subsection{Emissions of $\mathrm{NO}_{\mathrm{x}}$}

The tendency of NOx particulates for all fuel cases of current study with Brake Power are shown in Fig 10. For increased loads for varying fuel types, the volume of NOx emissions will increase for all cases. For Mahua Biodiesel share, a growth of $8.4 \%$ was observed compared to diesel. Because of enhanced inside cylinder temperatures due to oxygen accessibility NOx particulates raised than diesel. Further with metal-based additives of $\mathrm{Al}_{2} \mathrm{O}_{3}$ and $\mathrm{CuO}$, there is reduction of $4 \%$ \& $1.4 \%$ in emissions is found compared to the results of without additives with Biodiesel. This because of $\mathrm{Al}_{2} \mathrm{O}_{3}$ additive acts as a heat descend results to diminish of combustion temperature.

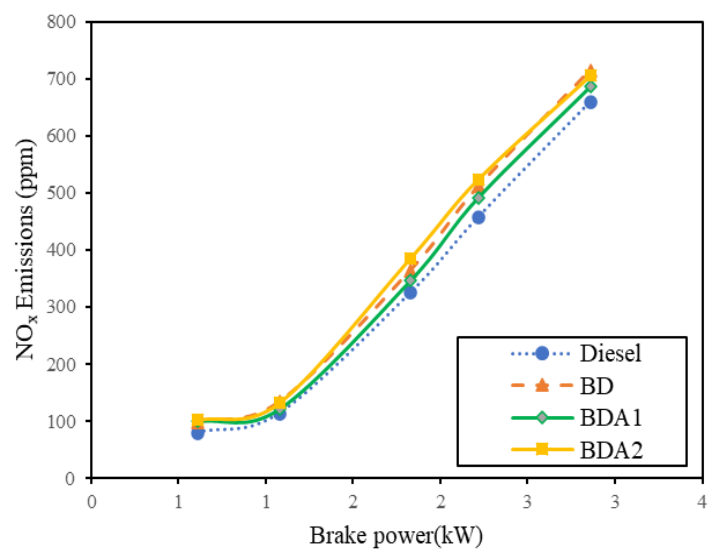

Fig 10. Variation of $\mathrm{NO}_{\mathrm{x}} v s \mathrm{BP}$

\section{Conclusions}

This study accounts the part of nano additives in achievement of parameters of combustion, efficiency and emission by Mahua Biodiesel used on existing diesel engine. The key points are summarized below:

$>$ The In-cylinder pressure and the HRR of Mahua biodiesel is less by $4 \%$ and $3.07 \%$ respectively compared to neat diesel operation due to low heating value of the biodiesel

$>$ Further, there is an improvement of about $5.7 \%$ \& $15.9 \%$ in cylinder pressure and $15.4 \%$ and $20.6 \%$ in HRR with Alumina \& $\mathrm{CuO}$ nano additives respectively with biodiesel is noted and this may be due to improvements in fuel combustion phenomena

$>$ Performance parameters, BTE improved nominally due to reduced heat loss and BSFC was increased by $2.5 \%$ due less volatility and viscosity of Mahua biodiesel

$>$ It was also observed that for BTE, there is a small enhancement of $0.5 \% \& 1.4 \%$ and a drop of $1.6 \%$ and $4 \%$ in BSFC with Oxides of $\mathrm{Al}_{2} \mathrm{O}_{3}$ $\mathrm{CuO}$ nano additives because of the larger areato-volume ratio of nanoparticles results quick desertion and increased atomization

$>\mathrm{HC}$ emissions were reduced by $16.2 \%, \mathrm{CO}$ emissions by $11.4 \%, \mathrm{CO}_{2}$ emissions by $5.2 \%$ with Mahua biodiesel over diesel case. An 8.4\% increase in NOx emissions with mahua fuel over diesel at rated load. Biodiesel exhibited higher cylinder temperatures due to the oxygen presence, which in turn enhanced the $\mathrm{NO}_{\mathrm{x}}$ particulates

$>$ with nano additives the mahua biodiesel receives additional oxygen which further improves the characteristics of combustion and particulates of emission

$>$ However, it was noticed that a decrease of $4 \%$ \& $1.4 \%$ with metal based nano additives of $\mathrm{Al} 2 \mathrm{O} 3$ and $\mathrm{CuO}$ in case of $\mathrm{NO}_{\mathrm{x}}$ particulates.

\section{Acknowledgement}

This research is executed under UGC grant reference number F. MRP-6740/16 (SERO/UGC), Special thanks to the monetary and rational support provided by the University Grant Commission (UGC) program to carry out research at GRIET.

\section{References}

1. Subramanian, K.A. Singal, S.K. Mukheshsaxena, Sudheer Singhal, Journal of biomass and Bio Energy, vol. 29, pp. 65-72 (2005)

2. Mohibbe Azam, Amtul, Nahar N.M, Journal of biomass and bioenergy, vol 29, pp.293-302 (2005) 
3. Sudheer nandi, American Journal of Engineering Research, vol 02, issue 10, pp. 22-479 (2013)

4. D.K.Bora, M.pally, V.Sanduja, SAE:10.4271/200428-0034 (2004)

5. S.Puhan, N. Vedaraman, B.V.B.Ram et al., Biomass Bio-energy, vol 28 pp. 87-93 (2005)

6. Jyothi U.S and Vijaya Kumar Reddy. K., SAE Technical Paper, doi:10.4271/2018-28-0057 (2018)

7. Arul Prakasajothi Mahalingam, Yuvarajan Devarajan et al., Alexandria Engineering Journal, volume 57, Issue 4, PP 2627-2631, (2018)

8. Choi, U.S, The American Society of Mechanical Engineers, Newyork, FED- Vol.231/MD- Vol.66, pp. 99-105 (1995)

9. U.S.Jyothi, K.Vijaya Kumar Reddy, ASME 10th International Conference on energy sustainability, ES2016-59164, pp. V001 to 2A003 (2016)

10. Vijayakumar Chandrasekharan, Murugesan Arthanarisamy, Transportation Research Part D 46 pp.145-146 (2016)

11. Harish Venu and Venkataramanan Madhavan, Journal of Mechanical Science and Technology 31 (1) pp. 409-420 (2017)

12. Tummala Suresh Kumar, Kosaraju Satyanarayana, Materials Today: Proceeding, 26 (2), 2020.

13. C.SyedAalam, C.G. Saravanan, Ain Shams Engineering Journal 8, pp. 689-696 (2017)

14. Chiranjeeva Rao Seela, B.Ravisankar, B.M.V.A.Raju, Egyptian Journal of Petroleum, 27, pp. 641-647(2018)

15. Harish Venu and Venkataramanan Madhavan, Journal of Mechanical Science and Technology 30 (5) pp. 2361-2368 (2016) 